\title{
CONSTRUCCIÓN VIRIL CON LA EXPERIENCIA FEMENINA EN LA CIUDAD Y LOS PERROS
}

\section{VIRILE CONSTRUCTION WITH THE FEMALE EXPERIENCE IN THE TIME OF THE HERO}

Referencia del ensayo

Delgado Del Aguila, J. M. (2022). Construcción viril con la experiencia femenina en la ciudad y los perros. Revista Científica del Sistema de Estudios de Postgrado de la Universidad de San Carlos de Guatemala, 5(1), 25-32. DOI: https://doi.org/10.36958/sep.v5i1.93

\author{
Jesús Miguel Delgado Del Aguila \\ tarmangani2088@outlook.com \\ https://orcid.org/0000-0002-2633-8101 \\ Doctorado en Literatura Peruana y Latinoamericana \\ Universidad Nacional Mayor de San Marcos, Perú
}

Fecha de aceptado: 05/01/2022

\section{ABSTRACT}

OBJECTIVE: to establish a taxonomy based on the women that are reflected in The Time of the Hero. Likewise, the role of each type found that is involved in the development of the cadets will be explained. METHOD: it will be confronted with the sociological theory and the critical studies that have been made on the literary work to determine to what extent the characters alluded to are in an inescapable correspondence with women. RESULTS: it was possible to classify the purpose of the types of women that are presented in the text and that are fundamental for the characters of that military institution. CONCLUSION: it was found that the inclusion of experiences with women in adolescents in Mario Vargas Llosa's novel was fundamental for their human development.

\section{KEYWORDS}

Hermeneutics, virility, learning, literary analysis, woman
Hermenéutica, virilidad, aprendizaje, análisis literario, mujer 


\section{INTRODUCCIÓN}

Este trabajo retoma los estudios críticos realizados en torno al tratamiento femenino en La ciudad y los perros, con el fin de reconocer la utilidad de la mujer en los personajes que están siendo sometidos a un adiestramiento castrense. Desde allí, lograrán su madurez y su autoestima, a la vez que forjan su identidad -encima, la violencia será ineludible para que ellos condensen su virilidad-. Sin embargo, existe otra inquietud: se presentan cualidades y prototipos heterogéneos. Teresa no se comporta igual a la Pies Dorados o a las madres de los protagonistas, por lo que en esta investigación distinguiré los roles de cada una y la función que cumplen.

Por otro lado, este ensayo científico se deriva de una parte de mi tesis de licenciatura, titulada Protagonismo violento y modos de representación en La ciudad y los perros (1963), la cual fue sustentada y publicada en el repositorio de la Universidad Nacional Mayor de San Marcos (Lima, Perú). Además, la totalidad de este trabajo de grado se encuentra en distintas plataformas de difusión de la investigación y de acceso libre, como en las páginas de Researchgate, Academia. edu, PhilPapers, entre otros.

\section{CONTENIDO}

\section{Abordaje hermenéutico de la mujer en La ciudad y los perros}

Este tema condiciona a colocar los géneros en dos planos, complementarios y contrapuestos, en los que la mujer es asumida como quien desempeña un rol de sumisión frente a la ideología que se instaura en una sociedad machista. Para ello, he seleccionado los cuatro criterios que ha investigado la crítica literaria.
El primer criterio es el machismo. Este implica un sometimiento forzado y que es aceptado por la mujer. Sövgren (2011), lo detecta desde el inicio de la obra y Díaz Reátegui (2004), precisa que este es fundamental para que los personajes construyan su identidad masculina, puesto que el universo femenino parece estar desintegrándose para ellos. Al respecto, Janků (2008), argumenta que la búsqueda de hombría tiene como finalidad relacionarse de manera óptima y brusca con los padres y los amigos; sobre todo, si se trata de una pandilla como el Círculo. Thays (2011), especifica que se retrata a una sociedad machista y falocéntrica, debido a la formación del carácter y el descubrimiento de la arbitrariedad del poder adulto, social o familiar, que se articula desde una adolescencia sin libertad. Con lo planteado, el machismo se aprecia como un constructo utópico al cual siguen los cadetes para desarrollarse, que a la vez es una propuesta de los militares, pero inestable. Ese carácter no ha sido detectado por la crítica literaria. Se sabe que adoptando una postura machista los personajes no tendrán éxito en lo que desean.

Esto sucede con el Poeta, el Jaguar y el Esclavo. El Poeta anhela conseguir una enamorada bonita y estable. El Jaguar pretende ser el líder durante su estancia en el colegio sin recibir maltrato; solo se someterá a lo ético y lo humanístico para subsanar su distanciamiento con Teresa y el cargo de conciencia por el asesinato que cometió. Y el Esclavo se manifestará al acusar al serrano Cava para lograr su libertad. El machismo tiene aquí una peculiaridad. Es tan solo una prueba, una constante provisoria, que se obviará si no resulta eficaz.

El segundo criterio es que la mujer es tomada como un estímulo o un complemento para el desarrollo viril en la novela. Davis (1981) menciona que esta es un canal entre los cadetes para alcanzar su nivel social concomitante. Magnarelli (1981), sostiene que las 
mujeres son un estímulo en la novela para estos personajes, quienes adquieren o conocen su masculinización; pero también son originadores de conflictos, como la traición, el deseo, el desamparo y la complicidad.

Arturo Fontaine (2011), señala que en La ciudad y los perros, la sexualidad es absorbida por una tendencia uniforme. Verbigracia, no es casual que los cadetes vayan con la misma prostituta y se enamoren de la misma chica. Sövgren (2011), especifica que la mujer en la novela se ve limitada a un espacio social y económico reducido, del cual es difícil desplazarse. Por otro lado, clasifica a las mujeres de esta obra literaria como buenas y malas, por lo que las primeras son las que plasman un estereotipo complaciente, pulcro y delicado, como lo es Teresa para el Esclavo, el Jaguar y el Poeta. Entretanto, para el caso de la segunda tipología, se trata de quienes ejercen el rol de prostitución para complacer a los hombres. Thays (2011), hace una taxonomía similar entre decentes y prostitutas, pero les proporciona más importancia a las segundas, debido a que ellas logran captar y atraer con eficacia a los hombres.

De Felipe (2012), precisa que el contacto con Teresa transforma negativamente al Poeta, puesto que traiciona a sus amistades. Así sea la mujer de cualidades positivas o negativas, tiene una función estimulante en el varón, tal como la han diferenciado Sövgren y Thays. En vez de ayudarlo, genera que este desarrolle su capacidad para discernir, y madure. Eso se aprecia en la experiencia con la Pies Dorados; sobre todo, cuando llama la atención al Poeta en un momento crucial: "¿Vamos a dormir una siesta o qué?” (Vargas Llosa, 2012, p. 127). Esa advertencia aminorará la vergüenza que padece el personaje por tener relaciones sexuales por primera vez.

El tercer criterio consiste en hipocresía femenina. Hancock (1975), menciona que en la novela la mujer es hipócrita en la elección, merced a que solo le importa el matrimonio; sobre todo, en el caso de Teresa. Entretanto, Gladieu (2013), afirma que más se trata de demostrar lo contrario: la existencia de una mujer comprometida. En torno a lo formulado por Hancock y Gladieu, sostengo que no prevalece la hipocresía con el personaje. Más bien, es una conveniencia en el momento de querer estar con algún otro chico. Por ejemplo, su afinidad con el Esclavo, es porque él es un cadete; con el Poeta, es debido a su posición socioeconómica; y con el Jaguar, por enseñarle algunos cursos y acompañarla. A lo largo de la narración, se aprecia cómo rechaza al Jaguar, ya que hay una actitud que no le gusta: es celoso y violento. El matrimonio se condiciona con el transcurso de los años, pero no es su necesidad, ella podría haber estado soltera y su vida no se alteraría en absoluto.

El cuarto criterio, es la presencia del triángulo amoroso, en el que se involucra a Teresa como participante principal. Ella desata interacciones complejas entre los protagonistas. Esto lo detecta Iwasaki (2011), y lo entiende como una oportunidad para luchar por la liberación. Por otro lado, en vez de relaciones, habría temores y admiración automática a ese paradigma viril que se focaliza en la preponderancia del hombre acerca de la mujer. Gallagher (2011), señala que la figura de Teresa es metafórica, debido a las tres posibilidades socioeconómicas que puede tener una mujer para relacionarse con estos tres personajes. De Felipe (2012), indica que Teresa es un nexo lisonjero entre ellos. En función de los planteamientos del triángulo amoroso, concuerdo con todo lo expuesto, a la vez que deslindo lo añadido por De Felipe, quien constituye a Teresa como condicionada por preferir a uno o varios chicos; pero más resulta que no es tanto esa peculiaridad por un personaje, sino que ella en sí es interesada. 
Esto se comprueba luego de mucho tiempo, cuando el Jaguar va a la playa y la ve con otro adolescente, además de ser cuidadosa por no revelar el secreto a los tres personajes principales sobre el encuentro que tiene con cada uno de ellos. La información que se extrae es por parte de los cadetes, no de ella misma. Al configurarse de esa manera a Teresa, permite que nunca se lleguen a confrontar el Poeta con el Jaguar, ni con el Esclavo frente a ella.

\section{Abordaje teórico de la mujer en la no-} vela de Mario Vargas Llosa

La constitución femenina es evocada y repudiada, debido a que aceptarla implica una negación de la hombría. El hombre es allí el símbolo de poder, mientras que la mujer carece de este. Verbigracia, la representación fémina que hace el Poeta en sus novelas pornográficas implica una descalificación. En ese sentido, los personajes más notorios son quienes viven el sexo como desviación. Eso acontece con el Boa al usar de modo grotesco a su perra Malpapeada, con quien tiene una relación sadomasoquista. Además, los chicos poseen una visión frustrada de la mujer. Por eso, optan por la prostitución y la asocian con el fracaso. Acerca de la Pies Dorados, ella constituye una imagen estereotipada de la prostituta. El hombre paga para satisfacerse sexualmente y la mujer se comercializa solo como objeto. El enfoque del otro tipo femenino de esta obra literaria se evidencia con Teresa. Por ejemplo, se señala que el Esclavo y el Jaguar asocian la figura de esta chica con la de sus madres. Por lo tanto, intentarán empatizar con ella, a pesar de que el amor en la novela es frustrado. El trato del Esclavo será de caballería al relacionarse con Teresa por medio de cartas; entretanto, para el Jaguar se complejizará un poco más, ya que también denigra la imagen femenina y recurre al robo. A la vez, prevalece una esperanza: ese placer no es tan destructivo como el de la violencia.
Para Vargas Llosa (2008), el enfoque degradado de la mujer se ha explayado más durante el tiempo; sobre todo, con la inserción de la figura de la prostituta en la sociedad. Ha ocurrido todo lo contrario: el sexo se ha liberado de tabúes y la mujer conquista una libertad sexual que en el mundo subdesarrollado es inexistente. Para el autor, el burdel también es producto de la perversa visión puritana que la religión cristiana posee del sexo, como un quehacer con el que lo más instintivo y bestial de la naturaleza humana se manifiesta. El autor añade que el burdel es la personificación del machismo (otro criterio primordial del subdesarrollo), la doble moral que lo engendra (una para el hombre y otra más reservada para la mujer) y la hipócrita duplicidad frente al sexo (en el matrimonio, se tienen relaciones sexuales con el ser que uno ama, mientras que en un burdel se paga por la satisfacción sexual de cada uno).

En este caso, reanudando lo argüido por la crítica literaria y el autor, retomaré con distinción el sentido adoptado de la mujer y propondré tres tipos constantes y conflictivos de representación en la novela.

El primer modelo es el de la mujer ideal (Teresa). Se trata de un personaje delicado, bueno, trabajador, esforzado, cumplidor, inocente y de condiciones económicas escasas. Ellas desarrollan los afectos en sus interrelaciones por encima de lo racional. Se socializa en silencio: no expresa sus deseos, su agonía y sus maltratos. Lleva su existencia adelante, sin traslucir sus problemas. En la vida de Teresa, interactúan amorosamente el Jaguar, el Poeta y el Esclavo. Ellos poseen el deseo de ser amados por ella, sin importar las circunstancias y los altercados que los distancie; verbigracia, el colegio o las conductas violentas. No obstante, después Teresa se casará con el más indicado: con el Jaguar, ya que no era de mucho interés para el Poeta y el Esclavo no era apto de entablar un enamoramiento por su timidez. 
El segundo modelo es el de la mujer frustrada (madres de los protagonistas). Es el típico caso de la madre que ha fracasado en el matrimonio, se ha divorciado y no cuenta con la presencia física y económica de su esposo. Estas mujeres son víctimas del machismo: son sometidas y reprimidas socialmente. También se plasman su dependencia económica y su escasa oportunidad de trabajo merecido y debidamente remunerado. Eso se aprecia en la novela, aunque se intenta mostrar una faceta hipócrita de desinterés, como sucede con la mamá del Poeta, quien rechaza todo apoyo de su esposo por sus faltas éticas (Vargas Llosa, 2012).

El tercer modelo es el de la mujer degradada (la Pies Dorados). En la novela, se alude a esa prostituta de pies blancos, pequeños y refinados, que es la preferida de los cadetes de la primera sección del $5 .^{\circ}$ año. Con ella, se observa el código machista impuesto en la sociedad, que consiste en el menosprecio hacia la mujer. Ella será tomada como un objeto que servirá para las modificaciones y los deseos que demanda un tipo de sociedad utópica y moderna, en el que funciona la cadena del hombre violento y la mujer, sin importar que surja un vínculo afectuoso. Verbigracia, en la relación del Jaguar y Teresa, se aprecia una búsqueda de goce desinteresado, ya que, mientras él la domina, no acarrea una actitud romántica para atraerla sentimentalmente -como sí la posee el Esclavo-. Tendrá que adaptarse y regular su conducta violenta frente a las mujeres. En cambio, con el Poeta, ha ocurrido algo distinto. Él promueve literariamente la figura de la prostituta a sus compañeros. Ellos se generan fantasías al leer las novelitas eróticas Lula, la chuchumeca incorregible, La mujer loca y el burro, La jijuna y el jijuno, Los placeres de Eleodora o Los vicios de la carne. Su contenido no es saludable, tal como se corrobora en un fragmento, una de sus novelitas pornográficas: "Tenía las piernas gordas, blancas y sin pelos.
Eran ricas y daba ganas de morderlas" (Vargas Llosa, 2012, pp. 163-164). Quienes realicen esa lectura lo harán para subsanar sus carencias acerca de ese presente cerrado, en el que no tienen mujeres a su disposición ni tampoco pueden fornicar. El único objetivo extraíble es complacer sexualmente a esos adolescentes de alguna manera, aunque el Poeta recurra también a sus ganancias que le genera escribir. Sin embargo, el motivo principal es el de tranquilizar esas ansias hormonales. El tipo de escritura que plantea el Poeta no se asemeja al que usaba con cortesía y caballerosidad al redactar sus cartas de amor. Más bien, allí opta por la contraparte de lo ofensivo y lo pornográfico. Pretende simpatizar y enamorar al destinatario con su discurso estético y su intención particular.

Análisis metateórico con respecto a la experiencia femenina

Para el Jaguar, el Poeta y el Esclavo, la mujer es un incentivo que los dinamiza para conseguir un cambio de identidad. Altera sus identidades, pero también esto es producto de la misma evolución humana. Esta ha ido progresando a partir de los sentimientos de soledad y frustración por los que atravesaron los personajes; sobre todo, en torno a sus experiencias con las mujeres. Todo ello será notorio mediante tres etapas.

La primera etapa se distingue por un alto nivel de confianza que permite que el individuo se desenvuelva con facilidad frente a las mujeres, además de poseer sabiduría acerca de ciertos temas. Allí se halla el Jaguar, quien es más directo en este tipo de tratos. Si necesita tener sexo, se irá a un prostíbulo; y si requiere enamorarse, lo conseguirá con artimañas, como ocurre con Teresa.

La segunda etapa es la intermedia. Allí el proceso aún se muestra imperfecto, por más 
intentos y experiencias que uno vaya adquiriendo. La forma de tratar y enamorar a una chica todavía no es la idónea. El Poeta se encuentra en esa posición, quien se pone a prueba en oportunidad heteróclitas. Desea aprender a conquistar y conocer nuevas modalidades afines. Eso se comprueba cuando él se acuesta con la Pies Dorados. Con el tiempo, demuestra ese aprendizaje en su entorno con Tico, Pluto, Marcela y otros, quienes lo retan con frecuencia: le presentan chicas, lo llevan a fiestas, comentan de gustos, recomiendan parejas, etc.

La tercera etapa se caracteriza por la timidez y la baja autoestima del individuo. El Esclavo se introduce en ese ámbito. Él no tiene voluntad ni osadía para conquistar a una mujer; aparte, es inexperto en el trato con ellas. Tendrá que recurrir al Poeta para que lo aconseje y le haga llegar una carta a Teresa.

En síntesis, estas tres etapas permiten conocer una instancia perenne en los personajes. Sin embargo, estas fijaciones también son dinámicas, se deconstruyen y se desvirtúan, ¿acaso el Esclavo no desea conquistar a Teresa, como sí lo han hecho el Poeta y el Jaguar? Por encima de todo, los personajes anhelan entablar una relación con una mujer. Saben que alcanzarla les será satisfactorio. Además, saben que para conseguirlo deben actuar con determinación -como el Jaguar-. Entonces, allí es donde la violencia será un complemento que conllevará ese ascenso radical que desestructurará el posicionamiento en una etapa inferior.

\section{CONCLUSIÓN}

La crítica literaria que se ha hecho de esta novela ha permitido orientar esta investigación a una taxonomía adecuada. En ella, se pueden considerar a tres tipos de mujeres que están presentes en la evolución de los personajes masculinos de la institución castrense. Estas modalidades se conforman por mujeres ideales (Teresa), frustradas (las madres de los protagonistas) y degradadas (la Pies Dorados). Esa distinción será importante, ya que suscita que se comprendan las necesidades del Jaguar, el Poeta o el Esclavo con respecto a situaciones concretas. Asimismo, se comprobó que estos personajes transitan por una identidad muy cambiante y transmutable.

\section{REFERENCIAS}

Davis, M. (1981). “Dress Gray y La ciudad y los perros: el laberinto del honor". Revista lberoamericana, 47(116-117), 117-126. http: / / doi.org/10.5195/reviberoamer.1981.3648

De Felipe, P. (2012). “Un cuarto de siglo en la búsqueda de la felicidad en tres novelas de Mario Vargas Llosa”. Contexto, 16(18), 85-101. http://erevistas.saber. ula.ve/index.php/contexto/article/ view/10724

Delgado Del Aguila, J. M. (2017). Protagonismo violento y modos de representación en La ciudad y los perros (1963) [Tesis]. Universidad Nacional Mayor de San Marcos. http://cybertesis.unmsm.edu.pe/ bitstream/handle/20.500.12672/6868/ Delgado_dj.pdf

Díaz Reátegui, K. (2004). Cuestiones de identidad, ficción y verosimilitud en la autobiografía latinoamericana: Antes que anochezca y La ciudad y los perros [Tesis]. Universidad de Georgia. https:// getd.libs.uga.edu/pdfs/diaz-reategui_ karen_200408_ma.pdf

Fontaine,A. (2011). “VargasLlosaen31 voces”. Estudios Públicos, (122), 5-14. https://www.cepchile. cl/cep/site/docs/20160304/20160304095632/ rev122_AFontaine.pdf 
Gallagher, D. (2011). "La fecunda aventura”. Estudios Públicos, (122), 589-597. https: / /www.cepchile.cl/cep/site/ docs/20160304/20160304095711/rev122 DGallagher_documento.pdf

Gladieu, M. M. (2013). "La ciudad y los perros, novela inaugural” (video). https: / / youtu.be/Z2rdcc4cH5s

Hancock, J. (1975). "Animalization and Chiaroscuro Techniques: Descriptive Language in La ciudad y los perros (The City and the Dogs)". Latin American Literary Review, 4(7), 37-47. https://www.jstor. org/stable/20118982

Iwasaki, F. (2011). "Historia secreta de una orgía. Las primeras novelas de Mario Vargas Llosa”. Estudios Públicos, (122), 138-156. https: / /www.cepchile.cl/cep/ site/docs/20160304/20160304095641/ rev122_Flwasaki.pdf

Magnarelli, S. (1981). "La ciudad y los perros. Women and Language". Hispania, 64(2), 215-225. https://www.jstor.org/ stable/341856

Sövgren, P. (2011). Mario Vargas Llosa y sus personajes femeninos. Un estudio de La ciudad y los perros y Travesuras de la niña mala [Tesina]. Universidad de Lund. ht- tps: / / lup.lub.lu.se/luur/download?fun$\mathrm{c}=$ downloadFile\&recordOId=1981955\&fileOld $=1982480$

Thays, I. (2011). “Poder, pene, erección, castración y machismo en la obra de Mario Vargas Llosa”. Estudios Públicos, (122), 467-488. https://www.cepchile.cl/cep/ site/docs/20160304/20160304095705/ rev122_IThays.pdf

Vargas Llosa, M. (2008). El viaje a la ficción, ensayo sobre Juan Carlos Onetti. Lima: Alfaguara.

Vargas Llosa, M. (2012). La ciudad y los perros. Italia: Real Academia Española.

\section{SOBRE EL AUTOR}

\section{Jesús Miguel Delgado Del Aguila}

Es candidato a doctor en Literatura Peruana y Latinoamericana por la Universidad $\mathrm{Na}$ cional Mayor de San Marcos. Calificó como investigador Concytec (Perú) y Conacyt (El Salvador). Participó en congresos y ha publicado en revistas indexadas sobre Literatura y Estudios Culturales.

\author{
Conflicto de intereses \\ Declara no tener ningún conflicto de intereses. \\ Declaración de consentimiento informado \\ El estudio se realizó, respetando el Código de ética y buenas prácticas editoriales de publicación. \\ Derechos de uso \\ Copyright@ 2022 por Jesús Miguel Delgado Del Aguila \\ Este texto está protegido por una licencia Creative Commons 4.0. Internacional
}

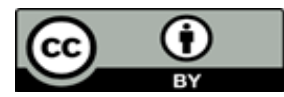

Usted es libre para compartir, copiar y redistribuir el material en cualquier medio o formato y adaptar el documento, remezclar, transformar y crear a partir del material para cualquier propósito, incluso comercialmente, siempre que cumpla la condición de atribución: usted debe reconocer el crédito de una obra de manera adecuada, proporcionar un enlace a la licencia, e indicar si se han realizado cambios. Puede hacerlo en cualquier forma razonable, pero no de forma tal que sugiera que tiene el apoyo del licenciante o lo recibe por el uso que hace. 